\title{
Alleviation of Picryl Chloride-Induced Delayed Type Hypersensitivity Reaction by Saponin Fraction of Gleditsia sinensis
}

\author{
Li-Fei Hou, ${ }^{a}$ Yue DAI, ${ }^{* a}$ Yu-Feng XIA, ${ }^{a}$ and Zhu-Nan GonG ${ }^{b}$ \\ ${ }^{a}$ Department of Pharmacology of Chinese Materia Medica, China Pharmaceutical University; 1 Shennong Road, Nanjing \\ 210038, China: and ${ }^{b}$ School of Life Sciences, Nanjing Normal University; Nanjing 210097, China. \\ Received November 18, 2005; accepted February 6, 2006
}

\begin{abstract}
The objective of the present study was to investigate the effects of saponin fraction from anomalous fruits of Gleditsia sinensis (SFGS) on picryl chloride-induced delayed type hypersensitivity (PC-DTH) and functions of T lymphocytes and macrophages in mice. SFGS $(100,200 \mathrm{mg} / \mathrm{kg})$, orally administered during either sensitization stage or effector stage, produced remarkable inhibition of PC-DTH. In vitro, SFGS $(1,2,4 \mu \mathrm{g} / \mathrm{ml})$ concentrationdependently attenuated concanavalin A (Con A)-elicited mouse splenocyte proliferation and interleukin 2 (IL-2) production. At concentrations of 10 and $20 \mu \mathrm{g} / \mathrm{ml}$, SFGS inhibited lipopolysaccharide (LPS)-induced production of nitric oxide and interleukin $1 \beta$ (IL-1 $\beta$ ) of mouse peritoneal macrophages. The findings indicate that SFGS attenuates PC-DTH in mice, which is probably mediated by preventing proliferation and differentiation of $T$ cells during the sensitization stage and suppressing activation of macrophages during the effector stage.
\end{abstract}

Key words Gleditsia sinensis; delayed type hypersensitivity; T lymphocyte; macrophage

Gleditsia sinensis LAM. (Leguminosae) is a perennial shrub widely distributed throughout China. The anomalous fruits of $G$. sinensis (AFGS) have long been known in traditional Chinese medicine as a saponin-rich herbal medicine for treating various diseases, such as apoplexy, headache, productive cough, asthma and scabies. ${ }^{1)}$ In previous studies, we demonstrated that the $70 \%$ ethanol extract of AFGS attenuated immunoglobulin E (IgE)-mediated immediate allergic reactions such as homologous passive cutaneous anaphylaxis in rats. ${ }^{2)}$ The $n$-butanol fraction from AFGS alleviated the early nasal symptoms of allergic rhinitis in rats via inhibiting histamine release from mast cells and nasal vascular permeability. ${ }^{3}$ ) Zhang et al. isolated and identified fifteen oleanane-type triterpenoidal saponins, called gleditsiosides, from the $n$-butanol fraction of AFGS. ${ }^{4-7)}$ These results suggest that saponins are the active constituents of AFGS responsible for the inhibitory properties on immune inflammation. The present study was designed to investigate effects of the saponin fraction from AFGS on delayed type hypersensitivity and functions of T lymphocytes and macrophages.

\section{MATERIALS AND METHODS}

Preparation of SFGS Samples of $G$. sinensis were purchased from the herbal market in Nanjing, China in May 2002. Its identity is confirmed as the anomalous fruits of $G$. sinensis LAM. by comparison with authentic specimens kept at the Herbarium, China Pharmaceutical University. A voucher specimen (Dai 0205) is deposited at the Department of Pharmacology of Chinese Materia Medica, China Pharmaceutical University. The saponin fraction (SFGS) was prepared in accordance with the method of Zhang et al. ${ }^{4,5)}$ with a slight modification. One and a half kilograms of $G$. sinensis fruits were ground and refluxed with $70 \%$ ethanol (151) three times for $1 \mathrm{~h}$. The ethanol extract was concentrated $(598 \mathrm{~g})$, suspended in water and then partitioned successively with petroleum ether, $n$-butanol and water. The $n$-butanol fraction $(300 \mathrm{~g})$ was applied to a column of macroporous resin D101 and the absorbed materials were eluted with water, 30, 50, and $70 \%$ ethanol. The 50 and $70 \%$ ethanol fractions, as saponin-rich fractions, were collected and lyophilized to give a dry extract $(117 \mathrm{~g})$.

Chemicals and Reagents Concanavalin A (Con A), naphthlyenediamine dihydrochloride, 3-[4,5-dimethyl-2-thiazolyl]-2,5-diphenyl-2H-tetrazolium bromide (MTT), sulphanilamide and lipopolysaccharide (LPS) were purchased from Sigma. Picryl chloride (PC) was purchased from Tokyo Kasei Kogyo Co. Ltd., Japan. Methyl- $\alpha$-D-mannopyranoside $(\alpha$-MM) was purchased from Fluka. Dexamethasone acetate was purchased from Zhejiang Xianju Pharmaceutical Co. Ltd. (Zhejiang, China). Interleukin 2 (IL-2) and interleukin $1 \beta$ (IL-1 $\beta$ ) commercial ELISA kits were purchased from Beijing North Institute of Biological Technology.

Animals Male ICR mice weighing 24-26g were obtained from the experimental animal center of China Pharmaceutical University (Nanjing, China) and BALB/c mice weighing $20-22 \mathrm{~g}$ were obtained from Sino-British Sippr/Bk Lab Animal Co. Ltd. (Shanghai, China). All animals were fed standard laboratory chow and water ad libitum. The environment was maintained at $22 \pm 2{ }^{\circ} \mathrm{C}$ with a $12 \mathrm{~h}$ light and dark cycle. Animal experiments were conducted in accordance with current ethical regulations on animal researches of China Pharmaceutical University and all animals used in experiments received humane care.

PC-Induced Delayed Type Hypersensitivity (PC-DTH) Male ICR mice were sensitized by applying $100 \mu \mathrm{l}$ of $1 \%$ PC dissolved in ethanol to the abdominal skin, shaved $24 \mathrm{~h}$ before. After $5 \mathrm{~d}$, animals were challenged by painting $30 \mu \mathrm{l}$ of $1 \%$ PC dissolved in olive oil on right ear lobes. The thickness of ear lobes was measured $24 \mathrm{~h}$ after the challenge using an engineer's micrometer, and ear swelling was represented as the thickness difference between right lobes and left ones. Test samples and dexamethasone were orally administered for consecutive $6 \mathrm{~d}$ from sensitization to challenge (sensitization stage) or for two times immediately and at $16 \mathrm{~h}$ after challenge (effector stage), respectively.

Preparation of Splenocytes and Thymocytes Splenocytes and thymocytes were obtained from BALB/c mice for 
in vitro studies. Briefly, spleens and thymuses were sterilely taken from normal mice and dissociated into single cell suspension in $5 \mathrm{ml}$ RPMI-1640 (Gibco) supplemented with 10\% heat-inactivated fetal calf serum (FCS), $2 \mathrm{~mm}$ L-glutamine, $1 \mathrm{~mm}$ sodium pyruvate, $100 \mathrm{U} / \mathrm{ml}$ penicillin and $100 \mu \mathrm{g} / \mathrm{ml}$ streptomycin (Sigma). The suspension was centrifuged at $200 \mathrm{~g}$ for $5 \mathrm{~min}$, and the supernatant was discarded. $0.17 \mathrm{M}$ tris(hydroxymethylaminomethane)- $0.75 \% \quad \mathrm{NH}_{4} \mathrm{Cl}$ solution was used to destroy erythrocytes. After washing with RPMI1640 for two times, cells were counted by trypan blue exclusion, and adjusted to needed density.

Cytotoxicity on Splenocytes One hundred microliters of splenocyte suspension $\left(5 \times 10^{6}\right.$ cells $\left./ \mathrm{ml}\right)$ was incubated in $96-$ well plates at $37^{\circ} \mathrm{C}$ in $5 \% \mathrm{CO}_{2}$ humidified air for $68 \mathrm{~h}$ with same volume of samples dissolved in RPMI-1640 with concentrations varying from 1 to $32 \mu \mathrm{g} / \mathrm{ml}$. Then, $20 \mu \mathrm{l}$ of MTT $(5 \mathrm{mg} / \mathrm{ml})$ was added for an additional $4 \mathrm{~h}$ incubation. After termination of incubation, the plates were centrifuged at $1000 \mathrm{~g}$ for $20 \mathrm{~min}$. Aspirating the supernatants, $200 \mu \mathrm{l}$ of dimethyl sulphoxide was added into each well to dissolve the formazan particles and the absorbance at $540 \mathrm{~nm}\left(\mathrm{OD}_{540}\right)$ was measured using a Model 450 Micro-plate Reader (BioRad, CA, U.S.A.).

Con A-Induced Splenocyte Proliferation The proliferation of splenocytes responding to Con A stimulation was evaluated using the method of MTT assay. ${ }^{8)}$ In brief, $100 \mu \mathrm{l}$ of splenocyte suspension $\left(5 \times 10^{6}\right.$ cells $\left./ \mathrm{ml}\right)$ was incubated with $50 \mu \mathrm{l}$ of Con A (final concentration $5 \mu \mathrm{g} / \mathrm{ml}$ ) and $50 \mu \mathrm{l}$ of various concentrations of samples in 96-well plates at $37^{\circ} \mathrm{C}$ in $5 \% \mathrm{CO}_{2}$ humidified air for $68 \mathrm{~h}$, and then $20 \mu \mathrm{l}$ of MTT $(5 \mathrm{mg} / \mathrm{ml})$ was added for an additional $4 \mathrm{~h}$ incubation. As described in cytotoxic test, $\mathrm{OD}_{540}$ value of each well was determined. The proliferation index was expressed as ratio of $\mathrm{OD}_{540}$ value of Con A-stimulated cells and that of non-stimulated cells.

Con A-Induced IL-2 Production In 24-well plates, $1 \mathrm{ml}$ of splenocyte suspension $\left(5 \times 10^{6}\right.$ cells $\left./ \mathrm{ml}\right)$ was cultured in medium alone or in medium containing Con A (final concentration $5 \mu \mathrm{g} / \mathrm{ml}$ ) in the presence or absence of samples for $48 \mathrm{~h}$ at $37^{\circ} \mathrm{C}$ in $5 \% \mathrm{CO}_{2}$ incubator. After the termination of incubation, the plates were centrifuged at $1000 \mathrm{~g}$ for $20 \mathrm{~min}$ and the supernatants were harvested. Content of IL-2 was determined by using ELISA kits according to the manufacturer's instructions.

LPS-Induced Nitric Oxide Production of Mouse Peritoneal Macrophages Mouse resident peritoneal exudate cells were harvested from BALB/c mice by lavaging with ice-cold RPMI-1640 supplemented with $1 \%$ heat-inactivated fetal calf serum $4 \mathrm{~d}$ after intraperitoneal injection of $2 \mathrm{ml}$ of $0.3 \%$ thyoglycollate broth (Wako Junyaku). ${ }^{9)}$ Cells were centrifuged at $4{ }^{\circ} \mathrm{C}$ for $7 \mathrm{~min}$ at $150 \mathrm{~g}$ and resuspended in RPMI1640 supplemented with $10 \%$ fetal calf serum. After counting by trypan blue exclusion, cells were then seeded in 96well cluster plates at a density of $2 \times 10^{6}$ cells $/ \mathrm{ml}$. After $2 \mathrm{~h}$ incubation at $37^{\circ} \mathrm{C}$ in $5 \% \mathrm{CO}_{2}$ humidified air, nonadherent cells were removed by washing twice with medium. The remained cells were incubated with medium containing various concentrations of samples and LPS $(10 \mu \mathrm{g} / \mathrm{ml})$ at $37^{\circ} \mathrm{C}$ for $24 \mathrm{~h}$. The supernatants were harvested for immediate determination of nitric oxide.

The nitric oxide (NO) produced by activated macrophages reacts rapidly with oxygen to produce nitrite. Therefore, nitrite levels in the supernatants of macrophage cultures were measured using Griess reaction. ${ }^{10)}$ The reactions were performed in triplicates by addition of $100 \mu \mathrm{l}$ of fresh supernatant to $100 \mu \mathrm{l}$ of Griess reagent $(0.1 \%$ naphthlyenediamine dihydrochloride $/ 1 \%$ sulphanilamide $\left./ 2.5 \% \mathrm{H}_{3} \mathrm{PO}_{4}\right)$. After incubation at room temperature for $15 \mathrm{~min}$, the absorbance was read at $570 \mathrm{~nm}$ using a Model 450 Micro-plate Reader (BioRad, CA, U.S.A.).

LPS-Induced IL-1 $\beta$ Production of Mouse Peritoneal Macrophages Mouse peritoneal macrophages were prepared and purified as described above. The cells were incubated with medium containing various concentrations of samples and LPS $(10 \mu \mathrm{g} / \mathrm{ml})$ in 24 -well plates at $37^{\circ} \mathrm{C}$ for $48 \mathrm{~h}$. The supernatants were harvested and stored at $-70^{\circ} \mathrm{C}$ until required for IL- $1 \beta$ assay. IL- $1 \beta$ was quantified by using ELISA kits according to the manufacturer's instructions.

Statistics The results are presented as means \pm S.D. Statistical significance between groups was tested by ANOVA and Dunnett's test. A probability value less than 0.05 was considered as significant.

\section{RESULTS}

Effect of SFGS on PC-DTH SFGS and dexamethasone were orally administered for consecutive six days from sensitization to challenge (sensitization stage) or for two times immediately and at $16 \mathrm{~h}$ after challenge (effector stage). Control mice received same volume of water $(20 \mathrm{ml} / \mathrm{kg})$. Figure 1A showed that SFGS $(100,200 \mathrm{mg} / \mathrm{kg})$ and dexamethasone $(7.5 \mathrm{mg} / \mathrm{kg})$, administered during sensitization stage, inhibited PC-DTH by 31.2, 54.2 and $69.7 \%$, respectively. Figure $1 \mathrm{~B}$ showed that SFGS $(100,200 \mathrm{mg} / \mathrm{kg})$ and dexamethasone $(7.5 \mathrm{mg} / \mathrm{kg})$, administered during effector stage, also inhibited PC-DTH by $50.5,58.0$ and $81.8 \%$, respectively.

Effects of SFGS on Con A-Induced Proliferation and IL-2 Production of Splenocyte In vitro, SFGS (1$8 \mu \mathrm{g} / \mathrm{ml}$ ) was cultured with mouse splenocytes for $72 \mathrm{~h}$, no evident cytotoxicity was observed. However, once the concentration of SFGS was higher than $16 \mu \mathrm{g} / \mathrm{ml}$, cytotoxicity appeared (Fig. 2A). SFGS (1, 2, $4 \mu \mathrm{g} / \mathrm{ml}$ ), cultured with mouse splenocytes for $72 \mathrm{~h}$, showed a concentration-dependent inhibition of Con A-induced proliferation. Significant in-
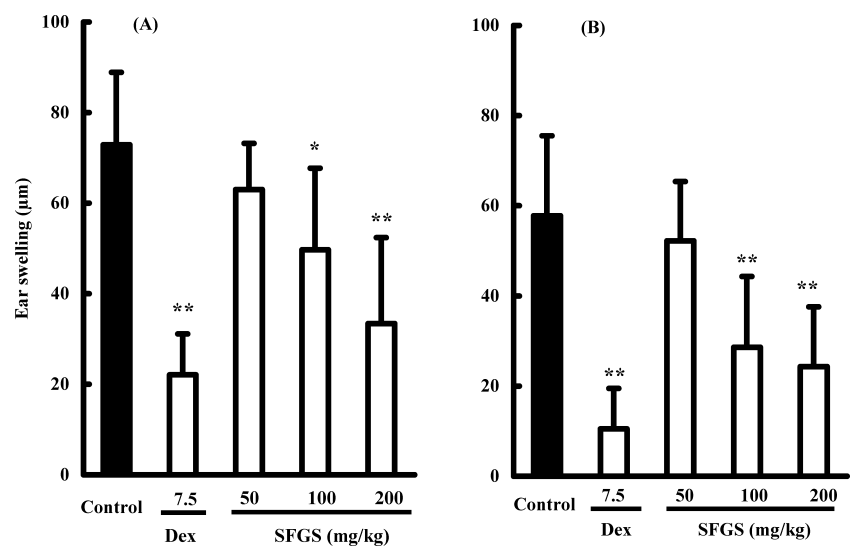

Fig. 1. Effects of SFGS and Dexamethasone (Dex) Administered during Sensitization Stage (A) or Effector Stage (B) on PC-DTH in Mice

Data are means \pm S.D. of 9 mice. $* p<0.05$, $* * p<0.01$. 

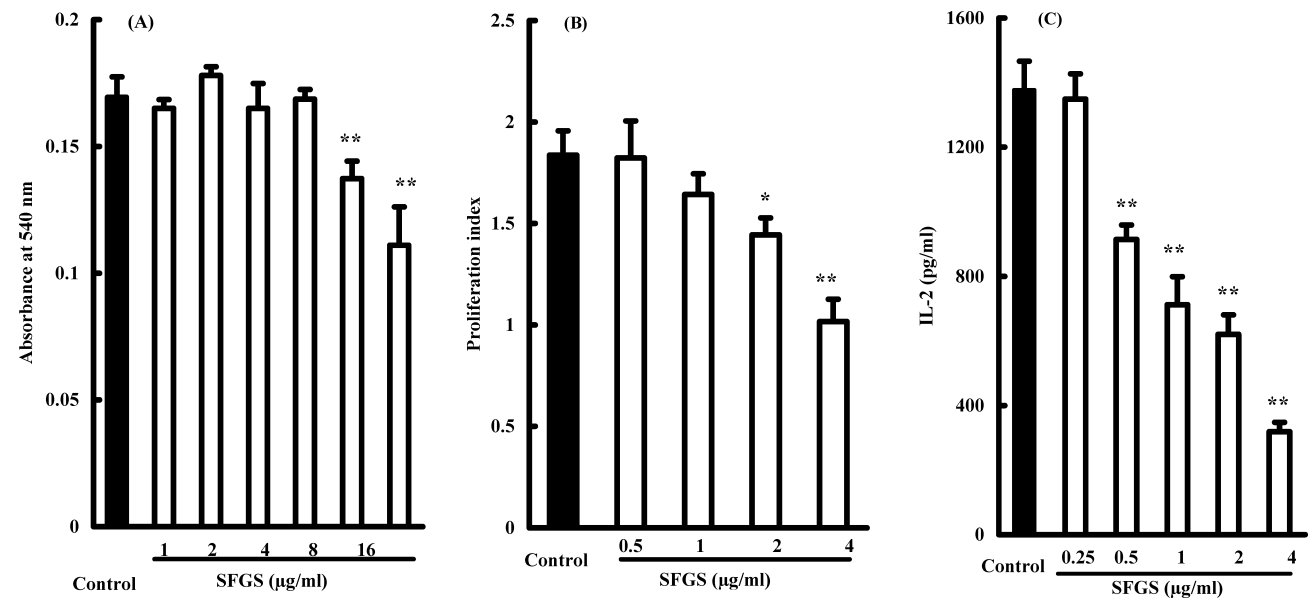

Fig. 2. Cytotoxicity of SFGS on Splenocytes (A) and Effects on Con A-Induced Proliferation (B) and IL-2 Production (C)

Data are means \pm S.D. of 3 experiments. $* p<0.05, * * p<0.01$.
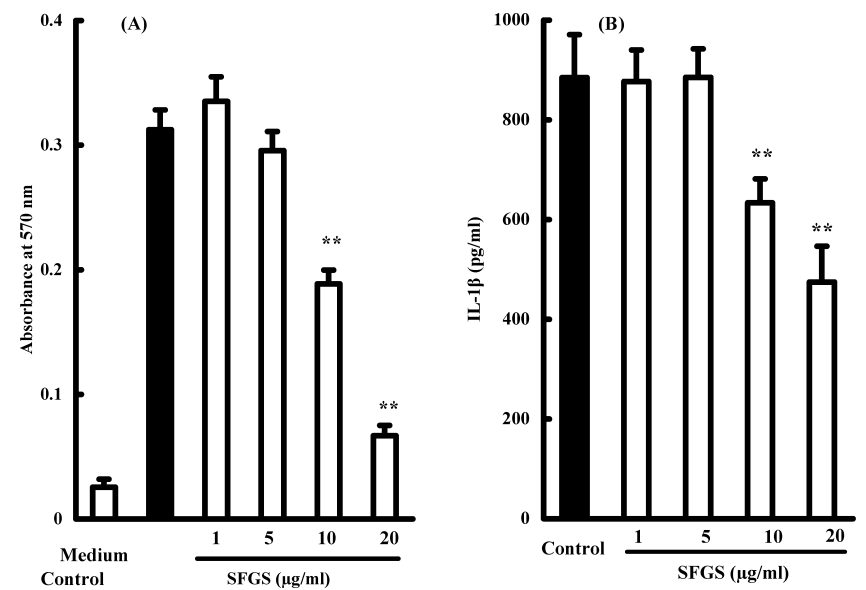

Fig. 3. Effects of SFGS on LPS-Induced Nitric Oxide (A) and IL-1 $\beta$ (B) Production from Peritoneal Macrophages

Data are means \pm S.D. of 3 experiments. $* * p<0.01$

hibitions were observed at concentrations of 2 and $4 \mu \mathrm{g} / \mathrm{ml}$ (Fig. 2B). On the other hand, SFGS $(0.5,1,2,4 \mu \mathrm{g} / \mathrm{ml})$ cultured with mouse splenocytes for $48 \mathrm{~h}$ could clearly attenuate Con A-induced IL-2 production. The inhibition percentages were 33.6, 48.3, 54.9 and 76.8\%, respectively (Fig. 2C).

Effects of SFGS on LPS-Induced Nitric Oxide (NO) and IL-1 $\beta$ Production from Peritoneal Macrophages As shown in Fig. 3A, SFGS $(5,10,20 \mu \mathrm{g} / \mathrm{ml})$, cultured with mouse peritoneal macrophages for $24 \mathrm{~h}$, reduced LPS-triggered NO production by $5.4,39.6$ and $78.6 \%$, respectively. Significant differences were observed at 10 and $20 \mu \mathrm{g} / \mathrm{ml}$. SFGS $(10,20 \mu \mathrm{g} / \mathrm{ml})$, cultured with mouse peritoneal macrophages for $48 \mathrm{~h}$, clearly reduced LPS-triggered IL- $1 \beta$ production (Fig. 3B). In preliminary experiments, we found that SFGS had no apparent effect on normal peritoneal macrophages of mice at concentrations below $50 \mu \mathrm{g} / \mathrm{ml}$, which suggested that inhibition of $\mathrm{NO}$ and IL- $1 \beta$ production by SFGS $(10,20 \mu \mathrm{g} / \mathrm{ml})$ was not due to cytotoxic effect.

\section{DISCUSSION}

PC-induced delayed type hypersensitivity (PC-DTH) is a typical in vivo manifestation of $\mathrm{T}$ cell-mediated immunity. It is characterized by activation and recruitment predominantly of $\mathrm{T}$ cells and macrophages and by resultant ear swelling at 24 to $72 \mathrm{~h}$. DTH reaction consists of two main stages, namely, the sensitization stage and the effector stage. In the former stage, primary exposure of antigen-specific $\mathrm{T}$ cells to peptide-MHC present on antigen-presenting cells (e.g., Langerhans cells in skin) results in proliferation of $\mathrm{T}$ cells and differentiation to type 1 helper $\mathrm{T}$ lymphocytes (Th1), which are driven by cytokines such as IL-1 and IL-2. In the latter stage, reexposure of Th1 cells to antigen elicits the activation of Th1 cells and production of cytokines, notably chemokines and IFN- $\gamma$, which recruit and activate mononuclear cells (mostly macrophages). Lysosomal enzymes, peroxide and superoxide radicals such as nitric oxide, performed by infiltrated macrophages, contribute predominantly to the eventual outcome of DTH reaction (exudation of plasma and local tissue damage). ${ }^{11)}$ It can be concluded that macrophages are necessary for appropriate development of DTH in spite of the central role of T lymphocyte.

The present study was conducted to investigate the effect of saponin fraction from anomalous fruits of $G$. sinensis (SFGS) on PC-DTH in mice. To elucidate the potential mechanism, we assessed influences of SFGS on functions of $\mathrm{T}$ lymphocytes and macrophages. Results have shown that SFGS, orally administered during either sensitization stage or effector stage, produced remarkable inhibition of PCDTH. In vitro, SFGS concentration-dependently attenuated Con A-elicited proliferation and IL-2 production of mouse splenocytes, inhibited LPS-induced production of IL-1 $\beta$ and nitric oxide from peritoneal macrophages of mice. The data suggest that inhibition of PC-DTH by SFGS is probably contributed by preventing proliferation and differentiation of $\mathrm{T}$ cells during the sensitization stage and attenuating activation of macrophages during the effector stage.

The emerging numerous articles reported that mast cells also play an important role in the process of $\mathrm{T}$ cell-mediated DTH reactions and autoimmune diseases. Activated mast cells are capable of producing large amounts of tumor necrosis factor $\alpha$ (TNF- $\alpha$ ) and CXC chemokines macrophage inflammatory protein-1 (MIP-1) $\alpha / \beta$ and MIP-2, which enhance DTH reactions by regulating the recruitment of polymorphonuclear leucocytes into sites of inflammation during the effector stage of DTH. ${ }^{12,13)}$ Our previous studies demon- 
strated that ethanol extract and $n$-butanol fraction from $G$. sinensis are able to prevent mast cell activation caused by compound 48/80 and consequent mediator release. ${ }^{2,3)}$ It is, therefore, postulated that restriction of mast cell activation may also contribute to inhibition of DTH by SFGS.

Gleditsiosides, bisdesmosidic triterpenoidal saponins isolated from SFGS, share a similar structural feature. The aglycon is echinocystic acid or oleanolic acid. There are a trisaccharide $[(\beta$-D-Xylopyranosyl- $(1 \rightarrow 2)-\alpha$-L-arabinopyanosyl- $(1 \rightarrow$ $6)$ - $\beta$-D-glucopyranoside)] affixed $\mathrm{C}$-3 and a tetrasaccharide $[(\beta$-D-xylopyranosyl)-( $1 \rightarrow 3)$ - $\beta$-D-xylopyranosyl- $(1 \rightarrow 4)-\alpha$-Lrhamnopyranosyl- $(1 \rightarrow 2)-\beta$-D-glucopyranosyl ester] attached to $\mathrm{C}-28$. Interestingly, the oligosaccharide chains at C-28 of some compounds are acylated with monoterpenic acids. ${ }^{4-7)}$ The unusual structural features should attract us making further investigations to isolate and identify the active compounds of SFGS.

\section{REFERENCES}

1) Jiangsu New Medical College, "Zhongyao Dictionary (Encyclopedia of Chinese Materia Medica)," Shanghai Scientific \& Technological
Press, Shanghai, 1979, pp. 1144-1145, 2198.

2) Dai Y., Chan Y. P., Chu L. M., But P. P. H., Biol. Pharm. Bull., 25, 1179-1182 (2002).

3) Fu L. J., Dai Y., Wang Z. T., Zhang M., Biol. Pharm. Bull., 26, 974 977 (2003).

4) Zhang Z., Koike K., Jia Z., Nikaido T., Guo D., Zheng J., J. Nat. Prod., 62, 740-745 (1999).

5) Zhang Z., Koike K., Jia Z., Nikaido T., Guo D., Zheng J., Phytochemistry, 52, 715-722 (1999).

6) Zhang Z., Koike K., Jia Z., Nikaido T., Guo D., Zheng J., Chem. Pharm. Bull., 47, 388-393 (1999).

7) Zhang Z., Koike K., Jia Z., Nikaido T., Guo D., Zheng J., J. Nat. Prod., 62, 877-881 (1999).

8) Lombardi P., Fournier M., Bernier J., Mansour S., Neveu P., Krzystyniak K., Int. J. Immunopharmacol., 13, 1073-1084 (1991).

9) Terawaki K., Nose M., Ogihara Y., Biol. Pharm. Bull., 20, 809-811 (1997).

10) Zinyama R. B., Bancroft G. J., Sigola L. B., Immunol., 104, 439-446 (2001).

11) MacMicking J., Xie Q. W., Nathan C., Annu. Rev. Immunol., 15, $323-$ 350 (1997).

12) Biedermann T., Kneilling M., Mailhammer R., Maier K., Sander C. A., Kollias G., Kunkel S. L., Hultner L., Rocken M., J. Exp. Med., 192, 1441-1452 (2000).

13) von Stebut E., Metz M., Milon G., Knop J., Maurer M., Blood, 101, $210-215$ (2003) 